УАK 316.34/.35

ББК 60.54

DOI 10.22394/1682-2358-2018-3-130-137

Ya.A. Tsukanov, post graduate student of the Sociology and Information Technology Department, Central Russian Institute of Management, Branch of the Russian Presidential Academy of National Economy and Public Administration

\section{THEORETICAL BASIS} FOR THE RESEARCH OF CROWDSOURCING AND SMART MOBS

Theoretical foundations of "smart mobs" and "crowdsourcing" are considered. Two groups of prerequisites for the formation of smart mobs based on the analysis and synthesis of the theory of G. Reinhold are identified. The correlation between the concepts of "crowdsourcing" and "smart mobs" is analyzed.

Key words and word-combinations: smart mobs, crowdsourcing, political participation.
Я.А. Цуканов, аспирант кафедри социологии и информационньих технологий Среднерусского института управления - филиала Российской академии народного хозяйства и государственной служби при Президенте РФ (етаil: yatsukanov@gmail.com)

\section{ТЕОРЕТИЧЕСКИЕ ОСНОВЫ ИССАЕАОВАНИЯ КРАУАСОРСИНГА И УМНОЙ ТОАПЫ}

Аннотацุия. Рассматриваются теоретические основы понятий «умная толпа» и «краудсорсинг». Выделяются две группы предпосылок возникновения умной толпы на основе анализа и синтеза теории Г. Рейнгольда. Анализируется соотношение понятий «краудсорсинг» и «умная толпа».

Ключевые слова и словосочетания: умная толпа, краудсорсинг, политическое участие.

B meme цемях Аля попытки свержения Аействующей власти (государственного переворота). Наблюдаются также сценарии цветных ревомюций на постсоветском пространстве. Аیя государства ставится задача в установцении истинных факторов возникновения подобных

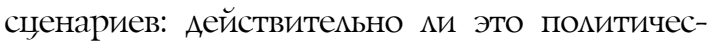
кое участие и волеизъявление большинства граждан страны или попытка государственного переворота, осуществцяемого небольшой группой миц. В современных реалиях толпа преобразовалась поА возАействием развития 
коммуникационных сред в виде мобильного Интернета. Возникли новые способы мобилизации, координации, рекрутинга участников Аля политической толпы. Изменились признаки самой толпы. Ресурсы толпы теперь можно использовать дмя решения общественных проблем, выполнения конкретных задач. Новый коммуникационный канац придал толпе не только форму, но и структуру. Появились способы группового Аавления на недобросовестного участника виртуацьной толпы, которые работают благодаря их репутационным системам. Аюди на умице могут быстро информировать Аруг Аруга, каждый может «быть глазами» дмя остальных. Остается актуальным вопрос о понятии механизма работы толпы, предпосылках их возникновения, способах контроця.

В современных реалиях существует феномен умной толпы (смартмоб), краудсорсинга, в которые включаются многие формы политического участия (ведение политических блогов, мобилизация сторонников политических партий/Авижений, подписание ониайн-петиџий, онлайн-анализ гражданами законотворческих инициатив парламентариев и т.А.). Традиционные формы помитического участия могут найти отражение в онлайн-виртуальности, которая строится с учетом закономерностей сотрудничества. ОАнако виртуальность Аопускает новые виды взаимодействия мюдей, недоступные при использовании традиџионных средств политического участия. Таким образом, Интернет дает возможность эвоцюџионировать всем формам политического участия, расширить масштаб политического взаимодействия.

С.Г. Ушкин в рамках своего диссертационного исследования приводит авторскую кАассификацию концепций сетевой протестной активности: теория умной толпы (Г. РейнгольА), теория минимизации затрат (К. Ширки, Е.А. Невесенко), теория сетей и потоков (М. Кастельс и Ар.), теория солидаризации и социального перфоманса (Аж. Александер, И.В. Ксенофонтова), теория слактивизма (Е. Морозов, 3. Бауман) [1, с. 53-64]. Автором отмечается главное разцичие межку сетевыми теориями - структурной разницей подходов, которая заключается «в эффекте влияния новых информационных и коммуникационных технологий на протестную активность: позитивном, негативном и нейтральном» [1, с. 63]. Попытаемся проанализировать некоторые из обозначенных теорий.

Термин «умная толпа» впервые предложия Г. Рейнгольд в 2002 г. SmartMob (англ. Smart mob - умная mолna) - форма самоструктурирующейся соџиальной организации, осуществцяющейся посредством эффективного использования высоких технологий [2, с. 8]. Ученый отмечает ситуативность их возникновения; взаимодействия между участниками умной толпы осуществляются, Ааже если они не знают Аруг Аруга. Признаки умной толпы соответствуют некоторым особенностям квазигруппы: анонимности, спонтанности образования, неустойчивости взаимосвязей, кратковременности совместных Аействий. Соџиальная структура межку участниками квазигруппы изначально отсутствует, но в определении умной толпы наличие социальной структуры четко определено - это форма самоструктурирующейся соџиальной организации. В виртуальности есть возможность отслеживать каждый шаг пользователя благоАаря системе учета и регистрации совершенных действий. Подобная система наблюдения раскрывает потенциал дия введения виртуальных репутационных 
систем, облегчающих взаимодействия между незнакомыми мюдьми. Наличие такой системы уже подразумевает существование виртуальной социацьной структуры. На основе репутационной системы возникает, как правило, система наказания (групповых форм социального контроля). В итоге умная толпа обладает признаками как соџиальной группы, так и квазигруппы.

В соответствии с положениями теории Г. Рейнгольда можно выделить Аве группы преАпосылок возникновения умной толпы:

- технологии сотрудничества, которые выполняют поиск решения задачи коммективного Аействия;

- развитие вычисличельной техники и коммуникационных сред (рисунок).

Под задачей комлективного действия понимается поиск равновесия, баланса межАУ потребностями кажАОй отАеАьно взятой мичности и необходимостью построения общественного блага. В качестве примера приведем пиринговые сети, где каждый их участник может совершать файлообменные операции. Сообщества таких сетей подразумевают, что каждый их участник Аолжен внести свой вклад в процесс файлообмена - это и будет явмяться условием существования общественного блага. Каждый участник пиринговых сетей может скачать выложкенный кем-то файл в мичных целях, но сообщество данной сети требует за эту корыстную операцию опреАеленной «платы» с участника. «Пиата» можкет заключаться в помощи Аругим пользователям скачать обозначенный файл (встать на раздачу) или в предоставлении Аанному сообществу новой информации (файла). Как и в реальности, виртуацьный участник может избегать «платы», истощая общественный ресурс, не предоставцяя ничего взамен. Аля решения подобной иждивенческой проблемы в виртуальности была перенесена из реальности система катацизаторов сотрудничества. Первым цогичным шагом по выявлению иждивенческих эмементов стало построение системы набцюдения, где функции контроця выполняет назначенный аАминистратор. Аیя выявления соотношения активности оАних участников по отношению к Аругим вводицись репутационные системы. Репутация кажАого участника зависит от ряда показателей основных индикаторов активности:

- сколько скачано (гигабайтой или терабайтов информации);

- сколько роздано (гигабайтой или терабайтов информации);

- количество выложенных файлов пользователя (торрентов);

- оказываемая помощь на форумах и т.А.

Ввод подобных репутационных систем выводия систему наблюдения за пользователями на новый уровень. Репутаџионные индикаторы позволяют выявцять иждивенческие эмементы сообществ и самых активных участников, внесших наибольший вклад в общественное благо. При наличии обозначенных систем развития сотрудничества в полной мере становится Аоступной система наказания и вознаграждения. Она может строиться как на поощрении активных участников, так и на наказании корыстных пользователей или иметь гибридную форму. В первом случае наказание иждивенческих эмементов имеет матентную форму: наиболее активные участники получают разцичные привияегии, тогда как недобросовестные участники их кишаются. Привилегии могут состоять из повышенной скорости скачивания, первоочередности скачивания, увекичения мимита скачиваемой информаџии и Аругого. Во втором 
случае иждивенческие элементы наказываются: снижкается мимит скачиваемой информации, скорость скачивания вплоть до изгнания из сообщества. В гибридной форме Аействуют как системы наказания, так и поощрения. Наказание и поощрение находятся в тесной связи с индикаторами систем набцюдения и репутации.

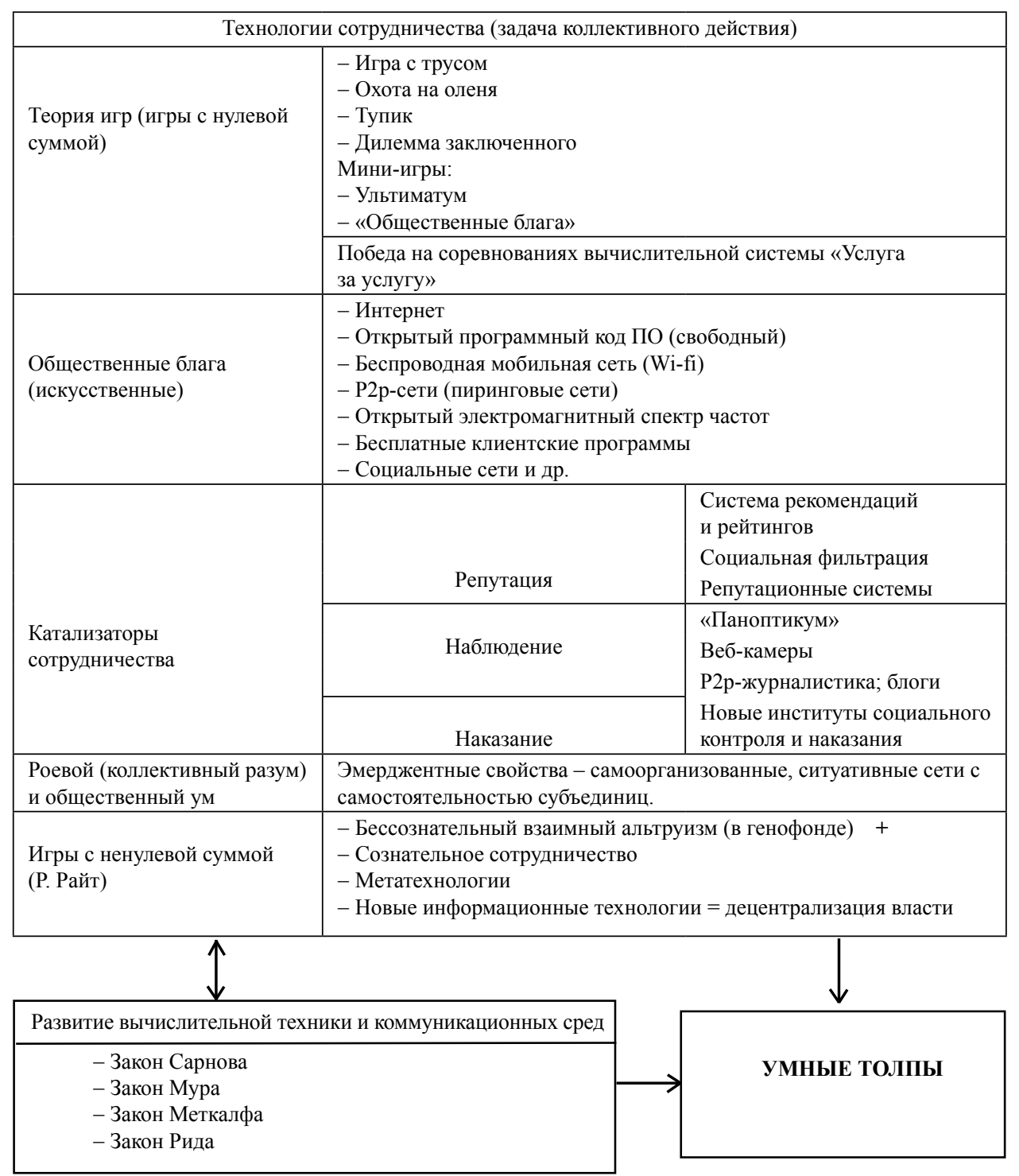

Группы предпосылок возникновения умной толпы в теории Г. Рейнгольда

Нельзя ограничить мимит скачиваемых торрентов конкретным пользователям (группе пользователей) без наличия соответствущего отслеживающего 
индикатора, отсюда и разность систем наказания в тех или иных сообществах. Рассмотренные катализаторы сотрудничества на примере сообществ пиринговых сетей явцяются оАним из признаков соџиальной группы. Как правило, все признаки соџиальной группы присущи яАру пользователей пиринговой сети, явцяющемуся незначительным в соотношении со всеми остацьными участниками файлообменного процесса. Большинство пользователей участвуют в раздачах спонтанно, анонимно, взаимодействуют Аруг с Аругом посреАством однообразного Аействия (скачивают необходимую информацию) в кичных целях. Это подтверждается многообразием торрент-трекеров, которые функщионируют без каких-либо систем развития сотрудничества, но существующих за счет торрент-трекеров с их наличием. Аля выделенных непостоянных пользователей характерны многие признаки квазигруппы, которые позволяют причислить пиринговые сети к теории умной толпы Г. Рейнгольда. ОАнако общественное благо в виде пиринговых сетей имеет и негативную сторону. Если Аля пирингового сообщества активные пользовате и, увеличивающие пределы общественного блага в пиринговых сетях, являются «честными» игроками, то Аля законных владелыев выкладываемой инфомации они иждивенџы. Аовольно часто файлы в пиринговых сетях размещаются без законных на то оснований. Владелец информаџии сталкивается с проблемой рассеивания искового заявления ввиду наличия множкества анонимных участников, скачавших файл. Первыми миџами дия судебных разбирательств становятся владельџы торренттрекеров, нередко явмяющиеся провайдерами. В этом случае выступает за-

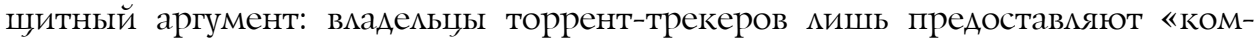
нату» Аля обмена данными, а за предмет обмена пользователей (контент) ответственности не несут. Роскомнадзор ведет активную борьбу с незаконным распространением информации в пиринговых сетях, но активность нелегального обмена на торрент-трекерах по-прежкнему высока.

Рассмотренные на примере пиринговых сетей виртуальные системы наблюАения, репутаций, наказаний имеют свой универсальный виА и в соџиальных сетях, в разцичных кциентских программах, на краудсорсинговых площадках, в виртуальных торговых площадках и т.А.

Вторую группу предпосыцок возникновения умной толпы Г. РейнгольА виАит в развитии вычисличельной техники и коммуникационных среА, ссылаясь на четыре основных закона: закон Мура, закон Сарнова, закон Меткалфа, закон Рида. Закон Мура достигает своего предела, что и было им обозначено (в физических пределах размера атома и скорости света). Оживленная дискуссия по данному вопросу началась в 2015 г. Остальные три закона относятся к развитию коммуникационных среА. Разбор законов в Аанной работе не имеет особого смысла, а их содержкание находится в открытом доступе. Отметим мишь то, что без появления и развития вычислительных и коммуникационных среА выбранный преАмет исследования будет отсутствовать.

Массовое участие, по мнению К. Ширки, претерпело следующие изменения: 1) коммуникации участников приобрели более горизонтальный характер; 2) появилась цифровая журналистика; 3) пользователь соџиальных сетей не только потребляет, но и производит свой контент [3]. Можно найти отражкение преАставценных постулатов и основной концепции теории мини- 
мизации затрат К. Ширки в теории умной толпы Г. Рейнгольда. Это заметно Ааже при взгляде на схему (рисунок): Г. Рейнгольдом были рассмотрены вопросы р2р-журналистики, вероятность угрозы от «информационного мусора» пользователей, непрерывно генерирующие контент. Минимизация затрат за счет самоорганизаџии участников заведомо заложена в опредемение умной толпы Г. Рейнгольда. Различны только маркеры участников: в одном случае это умная толпа, а в Аругом - участники виртуальных социальных сетей. Но К. Ширки внес значительный вклаА в разработку постулатов организации виртуальных сетевых участников в сетевые группы [4] .

Понятие «краудсорсинг» появимось позже теории умной толпы и связано с именем журналиста $A$. Хау, который в 2006 г. впервые в статье «The Rise of Crowdsourcing» в журнале «Wired» определил центральное понятие (англ. crowdsourcing, crowd - «толпа» и sourcing - «использование ресурсов») - это мобилизация ресурсов мюдей посредством информационных (и коммуникационных) технологий с целью решения задач, стояших перед бизнесом, государством и обществом в целом [5]. На данный момент преобцадают такие виды краудсорсинга, как краудфандинг и краудинвестинг. Сама трактовка краудсорсинга «ведет» к основному действующему киџу - толпе, которая существует в рамках информационных и коммуникационных технологий с высоким уровнем сотрудничества.

С.В. Егерев и С.А. Захарова приходят к мысли о том, что современная наука в российских реалиях может и должна строить и развивать платформы краудсорсинга с џелью расширения горизонтальных связей научного сообщества, проведения более масштабных и независимых исследований и способна отойти от более традиџионной иерархической системы взаимодействия ученых и начальства [6, с. 311-313]. Краудинвестинг и краудфандинг могут стать ключевыми источниками независимости исследователей. Отмечается наличие сетевой структуры «распределенных» квалифицированных каАров и научной деятельности, где поставлены определенные задачи и присутствуют ролевые компоненты дмя «подкмючаемых» участников. Обозначенные квалифиџированные кадры могут иметь две формы научной деятельности: сетевые и дисперсные. В сетевых сообществах, как правимо, присутствуют Аюди, чьим основным видом профессиональной занятости выступает научная деятельность и они, соответственно, причастны к традиционным научным организациям. Как уже отмечалось в примере о ядре пиринговых сетей, в сетевых научных сообществах присутствует более выраженная структура и взаимосвязь межАу участниками, сохраняются черты научной команды. Аисперсные сообщества отличаются большей степенью автономности, они разрозненны, а взаимосвязи участников менее устойчивы по причине ситуативности возникновения предлагаемой задачи и/или отсутствия запланированного круга исполнителей (участников). 3Аесь также может присутствовать ядро в виде профессионалов, но основная работа предназначается Амя периферии, состоящей из «любитемей». ОАной из отмеченных авторами проблем по развитию сетевой и дисперсной исследовательской деятельности в России явмяется отсутствие опыта призового вознаграждения больших групп участников - слабо проработанной системы вознагражжения и наказания. Аля опредемения понятия краудсорсин- 
га исследователи используют скорее исторический подход. В его рамках рядом зарубежных научных авторов исследуется комективная распределенная работа как прародитель современного понятия краудсорсинга [7; 8]. В заданном исследовательском ракурсе использование ресурсов толпы не имеет строгой привязки к такому коммуникационному каналу, как Интернет, и может существовать за счет средств массовой информации. Банальный конкурс, условия которого растиражированы на цистовках, есть пример краудсорсинга.

В отечественной науке краудсорсинг часто рассматривается как положительный феномен [9]. А.В. Акаев, Г.В. Макович отмечают наличие большого потенциала в использовании краудсорсинговых проектов по увеличению степени социальной активности населения $[10 ; 11]$. Степень такой активности зависит от образования обратной связи (власть - общество), возможность реализации которой явмяется неотъемлемой частью коммуникационных сетей в виде Интернета. ГАавный плюс краудсорсинга закмючается в пространственной, статусной, ролевой и иной разрозненности задействованных эмементов (участников) и самоорганизованности субъединиц по принципу ролевой системы, что позволяет кажАому участнику приносить свой фрагмент «мозаики» Амя составления общей Аинамичной соџиально-политической картины страны / области / города и совместного решения обозначенных проблем населения. Исходя из Аанных постуматов, краудсорсинг может стать амьтернативой ими даже заменой дорогостоящих социологических опросов - то есть прогнозируется минимизация ресурсозатрат за счет самоорганизации краудсорсинговых групп. Необходимо отметить, что не во всех работах краудсорсинг представлен в «светлых» тонах. Так, Е. Морозовым [12] и 3. Бауманом [13] предложена теория слактивизма. Авторы такого подхода не только не видят реального участия по сформированным в виртуальности принципам участия, но и предвещают угрозу тотального надзора вцастных структур в соџиально-политических виртуальных сетях. Следовательно, предпринимается попытка опровержения всех позитивных подходов к использованию краудсорсинговых платформ в соџиально-политических сферах участия.

На основе проведенного анализа можно сделать вывод, что понятия «краУАсорсинг» и «смартмоб» соотносятся слеАующим образом:

1) понятие «смартмоб» имеет определенную форму соџиальной организации;

2) часть определения краудсорсинга «мобилизация ресурсов» мюдей не исключает названную форму;

3) понятие «краудсорсинг» вкцючает множество форм взаимодействия на основе использования информационных и коммуникационных технологий;

4) понятия «смартмоб» и «краудсорсинг» не искАючают Аинамики используемых технологий (их смены);

5) оба понятия не исключают возможности действий субъектов оффлайн, но строго привязаны к использованию высоких технологий;

6) понятие «краудсорсинг» имеет четкую цель или задачу, которую необхоАимо решить; постановку цели или задачи осуществцяет конкретный заказчик;

7) в структуре краудсорсинга отсутствуют иждивенческие элементы в отмичие от умной толпы; участники умной толпы могут преследовать собственные цели в ущерб какого-то общественного блага. 
Таким образом, отмечается широкая представленность в отечественной и

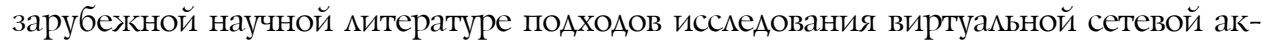
тивности (умной толпы) и краудсорсинга. Коммуникаџионные сети в виде Интернета и мобильного Интернета позволяют выстраивать старые (традиционные) формы взаимоотношений, взаимодействий и переносить их в новую виртуальную среду. Успешно существующие в реальности виды катализаторов сотрудничества были спроектированы вновь в виртуальности. Теперь каждый человек можкет спроектировать себя заново в виртуальности. Но обсуждаемая коммуникационная сеть Аает новый виток развития переносимым из реальности традиџионным смыслам. Группы мюдей стали приобретать признаки квазигруппы и социальной группы, и это не является переходным периодом, стадией, а указывает на существование среднего звена межАу квазигруппой и соџиальной группой. Г. РейнгольА одним из первых предпринял попытку маркировать это звено, где «толпа» выступает эталоном признаков квазигруппы, как в теориях Г. Тарда и Г. Аебона [14] , а «умная» соотносится с признаками сплоченной соџиальной группы. Понятие «краудсорсинг» возникло уже по причине наличия условных «средних» групп и из желания использования их ресурсов повсеместно. Понятия о массовой деятельности существовали и ранее, но только благодаря Интернету краудсорсинг приобрел жекаемый масштаб и форму.

\section{Библиографический список}

1. Ушкин С.Г. Влияние виртуальных социальных сетей на протестную активность в российском обществе: дис. ... канд. социол. наук. Саранск, 2015.

2. Рейнгольд Г. Умная толпа: Новая социальная революция / пер. с англ. А. Гарькавого. М., 2006.

3. Shirky C. How social media can make history. URL: http://www.ted.com/talks/clay_shirky_ how_cellphones_twitter_facebook_can_make_history/transcript

4. Shirky C. Here Comes Everybody: The Power of Organizing Without Organizations. United Kingdom: Penguin Group, 2008.

5. Мосс А. Что такое краудфандинг? // Crowdsourcing.ru: портал крауд-сервисов, 2006. URL: http://crowdsourcing.ru/article/what_is_the_crowdfunding

6. Егерев С.В., Захарова С.A. Краудсорсинг в науке // Социологический альманах / Институт социологии НАН Беларуси. 2015. С. 311-322.

7. Lakhani K.R., Jeppesen L.B., Lohse P.A., Panetta J.A. The Value of Openness in Scientific Problem Solving // Power. 2013.

8. Winchester S. The Professor and the Madman: A Tale of Murder, Insanity, and the Making of the Oxford English Dictionary. Harper Collins USA, 1998.

9. Акаев Д.В. Использование краудсорсинговых интернет-проектов в социально-политических процессах // Вестник Поволжской академии государственной службы. 2013. № 4. С. 56-60.

10. Акаев Д.В. Социально-политическая активность участников интернет-сообществ // Среднерусский вестник общественных наук. 2014. № 4. С. 45-48.

11. Макович Г.В. Перспективы использования социальной активности населения: потенциал краудсорсинговых проектов // Вестник Поволжской академии государственной службы. 2016. № 2. C. 82-88.

12. Бауман 3. Способны ли Facebook и Twitter помочь распространению демократии и прав человека? // Русский журнал. URL: http://russ.ru/Mirovaya-povestka/Sposobny-li-Facebook-iTwitter-pomoch-rasprostraneniyu-demokratii-i-prav-cheloveka.

13. Morozov E. The Net Delusion: The Dark Side of Internet Freedom. N.Y., 2012.

14. Психология толп. М., 1998. 